\title{
Article \\ Health Risk Assessment of VOCs from Surgical Smoke
}

\author{
Shaohua She ${ }^{1}$, Gang Lu ${ }^{1}$, ${ }^{*}$ Wah Yang ${ }^{2}$, Mianwei Hong ${ }^{1}$, and Lingfei Zhu ${ }^{1}$ \\ 1 School of Environment, Guangzhou Key Laboratory of Environmental Exposure and Health, and \\ Guangdong Key Laboratory of Environmental Pollution and Health, Jinan University, Guangzhou 510632, \\ China. \\ 2 Department of General Surgery, the First Affiliated Hospital of Jinan University, Guangzhou 510630, China; \\ yangwah@qq.com \\ * Correspondence: tlugang@jnu.edu.cn; Tel.: +86-159-8928-4166 \\ Shaohua She and Gang Lu contributed equally to this work.
}

\begin{abstract}
Surgical smoke is produced by energy-based surgical instruments. The airborne volatile organic compounds (VOCs) from surgical smoke may have potential health risk. This study aimed to evaluate the evidence for the harmful effects on the operating theater staff. An internationally recognized evaluation model of health risk assessment (HRA) was adapted to preliminarily assess the health risks caused by VOCs in surgical smoke. Results of HRA indicated that non-carcinogenic risk indexes of VOCs did not exceed one, indicating that these pollutants didn't cause significant non-carcinogenic harm to the health of the operating theater staff. But the cancer risk indexes exposed to formaldehyde and benzene all exceed $10^{-5}$, which was higher than the suggested value of USEPA $\left(10^{-6}\right)$ and might cause potential harm to the health of the operating theater staff. Long-term exposure of such surgical smoke will be harmful to the health of the operating theater staff and have a great risk of cancer.
\end{abstract}

Keywords: surgical smoke; volatile organic compounds (VOCs); health risk assessment (HRA); carcinogenic

\section{Introduction}

With the development of modern medical technology and the frequent application of minimally invasive surgery, the use of electrotome and ultrasonic scalpel has increased [1]. Minimally invasive surgeon and operating theatre staff regularly are exposed to surgical smoke pollution produced by thermal tissue destruction. Gaseous byproducts produced during laser surgery, electrocautery or the use of ultrasonic scalpels are usually referred to as 'surgical smoke' [2]. Surgical smoke poses a significant health risk as a pulmonary irritant, carcinogen, and vector for transmitting infectious particles [3,4].

Surgical smoke is composed of $95 \%$ water vapour and $5 \%$ combustion by-products and cellular debris $[5,6]$. But it is cellular debris which accounts for less than $5 \%$ that makes surgical smoke threaten human health [7]. Confirmed by relevant institutions, the particles contain blood and fragment of tissue, harmful chemicals, active virus, living cells, inert particles, mutagen, etc. The chemicals present in greatest quantity in surgical smoke are hydrocarbons and nitriles, with hydrogen cyanide, formaldehyde and benzene representing the greatest hazards [8]. Surgical smoke exposure may increase the risk of acute or chronic pulmonary conditions, such as asthma, lung cancer or nasopharyngeal carcinoma $[9,10]$.

Harmonization of risk assessment approaches for occupational and environmental settings as well as for both cancer and non-cancer endpoints will be necessary for an integrated assessment to support a risk management decision. Occupational exposure limits sometimes exceed known effect levels. Environmental Protection Agency (U.S. EPA) derived values are intended to be protective of sensitive individuals, applying a default uncertainty factor for differences among humans. An 
Integrated risk information system (IRIS) assessment includes the first two steps of the risk assessment process: Hazard Identification, which identifies credible health hazards associated with exposure to a chemical. Dose-Response Assessment, which characterizes the quantitative relationship between chemical exposure and each credible health hazard [11]. These quantitative relationships are then used to derive toxicity values.

The objective of this study was to assess the health risks from inhalation exposure to VOCs in surgical smoke. Then exposure assessment with the hazard information and toxicity values from IRIS were combined to characterize potential operating theatre health risks. The reason to select formaldehyde and benzene as the target VOCs is that they have been ranked top on the list of VOCs with cancer risk potency greater than 1 per million population in the U.S. [12-14].

\section{Materials and Methods}

\subsection{Data Sources}

The data in Table 1 were mainly from literatures [15-17]. All experiments were performed over 20 min on commercialised pork meat or pork liver from fresh slaughtering, including the adherent

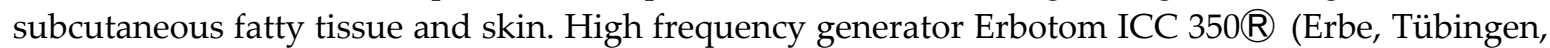
Germany) for electrocautery, the Ultracision G 220R (Ethicon, Hamburg,Germany) as harmonic scalpel, and Beamer-ONE ICC 350R (Erbe, Tübingen, Germany) for argon beaming were applied. Using standard settings, the routine application in the operating room was reproduced. The experiments were done in a laboratory with controlled air flow (Table 1). Each aerosol was absorbed by a standard filter system at a distance of $50 \mathrm{~cm}$.

Table 1. The concentration of the surgical smoke emission point i.e., leak source $\left(\mathrm{Q}_{0}\right)$ Units: $\mathrm{mg} / \mathrm{m}^{3}$

\begin{tabular}{|c|c|c|c|c|}
\hline 1 & \multicolumn{4}{|c|}{ electrocautery, $120 \mathrm{~W}$, cutting mode, liver } \\
\hline 2 & \multicolumn{4}{|c|}{ electrocautery, $120 \mathrm{~W}$, coagulation mode, liver } \\
\hline 3 & \multicolumn{4}{|c|}{ electrocautery, $120 \mathrm{~W}$, cutting mode, fatty tissue } \\
\hline 4 & \multicolumn{4}{|c|}{ electrocautery, $120 \mathrm{~W}$, cutting mode, fatty tissue } \\
\hline $\begin{array}{c}\text { chemical } \\
\text { composition } \\
\left(\mathrm{mg} / \mathrm{m}^{3}\right)\end{array}$ & 1 & 2 & 3 & 4 \\
\hline formaldehyde & 0.14 & 0.10 & 0.19 & 0.30 \\
\hline benzene & $158.7 \times 10^{-3}$ & $39.0 \times 10^{-3}$ & $13.0 \times 10^{-3}$ & $74.0 \times 10^{-3}$ \\
\hline toluene & $141.0 \times 10^{-3}$ & $39.1 \times 10^{-3}$ & $5.5 \times 10^{-3}$ & $31.6 \times 10^{-3}$ \\
\hline ethyl benzene & $31.8 \times 10^{-3}$ & $8.1 \times 10^{-3}$ & $5.7 \times 10^{-3}$ & $6.3 \times 10^{-3}$ \\
\hline o-xylene & $6.0 \times 10^{-3}$ & $0.9 \times 10^{-3}$ & $1.8 \times 10^{-3}$ & $1.3 \times 10^{-3}$ \\
\hline styrene & $20.1 \times 10^{-3}$ & $3.8 \times 10^{-3}$ & $4.3 \times 10^{-3}$ & $4.8 \times 10^{-3}$ \\
\hline naphthalene & $16.2 \times 10^{-3}$ & $<0.1 \times 10^{-3}$ & $31.0 \times 10^{-3}$ & $<0.1 \times 10^{-3}$ \\
\hline
\end{tabular}

\subsection{Gaussian Model}

To forecast the pollution area and the diffusion path of surgical smoke accurately, location in the operating room was taken into consideration. The elevated point source model, which is based on Gaussian diffusion model, was proposed for the simulation of surgical smoke diffusion process [18]. Gaussian models are based on a simple analytical formulation of concentrations and it has been validated against a wide range of data sets $[19,20]$.

According to the Gaussian model, the source of the leakage was the origin and the direction of the wind was the axis. In a space coordinate system, the concentration at one point $(x, y, z)$ was:

$$
C(x, y, z, H)=\frac{Q_{0}}{2 \pi V \sigma_{\mathrm{y}} \sigma_{x}} \times \exp \left(-\frac{y^{2}}{2 \sigma_{y}^{2}}\right) \times\left\{\exp \left[-\frac{(z-H)^{2}}{2 \sigma_{z}^{2}}\right]+\exp \left[-\frac{(z+H)^{2}}{2 \sigma_{z}^{2}}\right]\right\}
$$


Where $C(x, y, z, H)$ represents the concentration at the point of space $\left(\mathrm{kg} / \mathrm{m}^{3}\right), Q_{0}$ represents leak source $(\mathrm{kg} / \mathrm{s}), V$ represents the wind speed $(\mathrm{m} / \mathrm{s}), \sigma_{x}$ represents leeward diffusion coefficient $(\mathrm{m}), \sigma_{y}$ represents crosswind diffusion coefficient $(\mathrm{m}), \sigma_{z}$ represents vertical diffusion coefficient $(\mathrm{m}), H$ represents leak height $(\mathrm{m})$.

$Q_{0}$ in Table 2 was available and was converted from table 1 . According to the actual situation of operation room (Figure 1), the selection of related parameters were as the followings: $H=0.75 \mathrm{~m}$ (It refers to the height of the operating table.), $x=0.240 \mathrm{~m}$ (It refers to half the width of the operating table.), $y=0, z=1.544 \mathrm{~m}$ [It refers to the average height of Chinese men $(1.671 \mathrm{~m})$ and the proportion of human nose to the feet (0.924).], $V=0.1 \mathrm{~m} / \mathrm{s}$ (It is based on the wind speed of the fresh air system in the operating room.), $\sigma_{x}=\sigma_{y}=0.498, \sigma_{z}=0.293$. The smoke concentration after diffusion was calculated by this model (Table 3,4$)$.

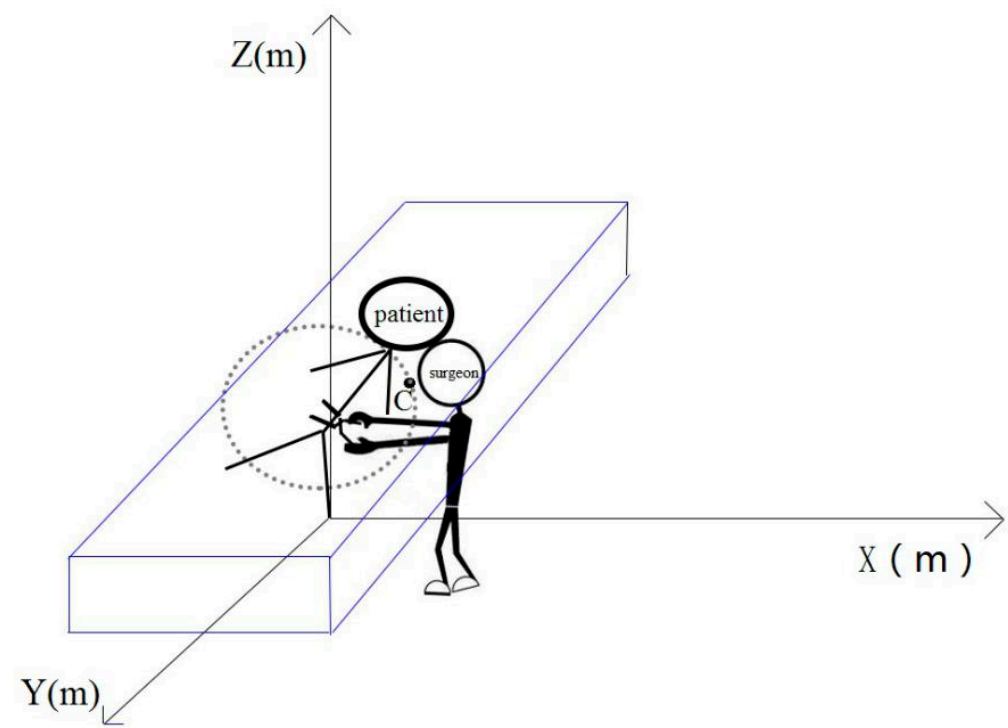

Figure 1. The schematic diagram of operation room (patient lay low and surgeon handle the minimally invasive scalpel)

Table 2. The concentration of the surgical smoke emission point i.e., leak source $\left(Q_{0}\right)$. Units: $\mathrm{kg} / \mathrm{s}$

\begin{tabular}{ccccc}
\hline $\begin{array}{c}\text { chemical } \\
\text { composition } \\
\mathbf{( k g / s )}\end{array}$ & $\mathbf{1}$ & $\mathbf{2}$ & $\mathbf{3}$ & $\mathbf{4}$ \\
\hline $\begin{array}{c}\text { formaldehyde } \\
\text { benzene }\end{array}$ & $1.17 \times 10^{-10}$ & $8.33 \times 10^{-11}$ & $1.58 \times 10^{-10}$ & $2.50 \times 10^{-10}$ \\
toluene & $1.32 \times 10^{-10}$ & $3.25 \times 10^{-11}$ & $1.08 \times 10^{-11}$ & $6.17 \times 10^{-11}$ \\
ethyl benzene & $1.18 \times 10^{-10}$ & $3.26 \times 10^{-11}$ & $4.58 \times 10^{-12}$ & $2.63 \times 10^{-11}$ \\
o-xylene & $2.65 \times 10^{-11}$ & $6.75 \times 10^{-12}$ & $4.75 \times 10^{-12}$ & $5.25 \times 10^{-12}$ \\
styrene & $5.00 \times 10^{-12}$ & $7.50 \times 10^{-13}$ & $1.50 \times 10^{-12}$ & $1.08 \times 10^{-12}$ \\
naphthalene & $1.68 \times 10^{-11}$ & $3.17 \times 10^{-12}$ & $3.58 \times 10^{-12}$ & $4.00 \times 10^{-12}$ \\
\hline
\end{tabular}


Table 3. The concentration of surgical smoke that surgeon inhaled i.e., the concentration at one point (0.240, 0, 1.544). Unit: kg/m³

\begin{tabular}{ccccc}
\hline $\begin{array}{c}\text { chemical composition } \\
\left(\mathbf{k g} / \mathbf{m}^{\mathbf{3}} \mathbf{)}\right.\end{array}$ & $\mathbf{1}$ & $\mathbf{2}$ & $\mathbf{3}$ & $\mathbf{4}$ \\
\hline formaldehyde & $1.91 \times 10^{-11}$ & $1.36 \times 10^{-11}$ & $2.58 \times 10^{-11}$ & $4.08 \times 10^{-11}$ \\
benzene & $2.15 \times 10^{-11}$ & $5.30 \times 10^{-12}$ & $1.76 \times 10^{-12}$ & $1.01 \times 10^{-11}$ \\
toluene & $1.93 \times 10^{-11}$ & $5.32 \times 10^{-12}$ & $7.47 \times 10^{-13}$ & $4.29 \times 10^{-12}$ \\
ethyl benzene & $4.32 \times 10^{-12}$ & $1.10 \times 10^{-12}$ & $7.75 \times 10^{-13}$ & $8.57 \times 10^{-13}$ \\
o-xylene & $8.16 \times 10^{-13}$ & $1.22 \times 10^{-13}$ & $2.45 \times 10^{-13}$ & $1.76 \times 10^{-13}$ \\
styrene & $2.74 \times 10^{-12}$ & $5.17 \times 10^{-13}$ & $5.84 \times 10^{-13}$ & $6.53 \times 10^{-13}$ \\
naphthalene & $2.20 \times 10^{-12}$ & $<1.36 \times 10^{-14}$ & $4.21 \times 10^{-12}$ & $<1.36 \times 10^{-14}$ \\
\hline
\end{tabular}

Table 4. The concentration of surgical smoke that surgeon inhaled i.e., the concentration at one point $(0.240,0,1.544)$. Unit: $\mathrm{mg} / \mathrm{m}^{3}$

\begin{tabular}{ccccc}
\hline $\begin{array}{c}\text { chemical composition } \\
\left(\mathbf{m g} / \mathbf{m}^{3}\right)\end{array}$ & $\mathbf{1}$ & $\mathbf{2}$ & $\mathbf{3}$ & $\mathbf{4}$ \\
\hline formaldehyde & $1.91 \times 10^{-5}$ & $1.36 \times 10^{-5}$ & $2.58 \times 10^{-5}$ & $4.08 \times 10^{-5}$ \\
benzene & $2.15 \times 10^{-5}$ & $5.30 \times 10^{-6}$ & $1.76 \times 10^{-6}$ & $1.01 \times 10^{-5}$ \\
toluene & $1.93 \times 10^{-5}$ & $5.32 \times 10^{-6}$ & $7.47 \times 10^{-7}$ & $4.29 \times 10^{-6}$ \\
ethyl benzene & $4.32 \times 10^{-6}$ & $1.10 \times 10^{-6}$ & $7.75 \times 10^{-7}$ & $8.57 \times 10^{-7}$ \\
O-xylene & $8.16 \times 10^{-7}$ & $1.22 \times 10^{-7}$ & $2.45 \times 10^{-7}$ & $1.76 \times 10^{-7}$ \\
styrene & $2.74 \times 10^{-6}$ & $5.17 \times 10^{-7}$ & $5.84 \times 10^{-7}$ & $6.53 \times 10^{-7}$ \\
naphthalene & $2.20 \times 10^{-6}$ & $<1.36 \times 10^{-8}$ & $4.21 \times 10^{-6}$ & $<1.36 \times 10^{-8}$ \\
\hline
\end{tabular}

\subsection{Health Risk Assessment}

\subsubsection{Non-carcinogenic health risk assessment}

The non-carcinogenic health risks associated with Indoor air quality (IAO) of the surgical smoke were evaluated in terms of the threshold mechanisms of toxic effects. Quantitative risk characterization involved a simple calculation of a hazard index $(H I)$.

$$
H I=\frac{C D I}{R \mathrm{f} D}
$$

Where CDI (chronic daily intake) represents inhalation exposure level of a given air toxic species $\left[\mathrm{mg} \cdot(\mathrm{kg} \cdot \mathrm{d})^{-1}\right]$ and $R f D$ (reference dose) represents a "threshold dose" of a given air toxic species $\left[\mathrm{mg} \cdot(\mathrm{kg} \cdot \mathrm{d})^{-1}\right]$.

$$
C D I=\frac{\mathrm{c} \times I R \times E D \times E F}{B W \times A L}
$$

Where $c$ represents pollutant concentration $\left(\mathrm{mg} \cdot \mathrm{m}^{-3}\right), I R$ represents inhalation rate $\left(\mathrm{m}^{3} \cdot \mathrm{d}^{-1}\right), E D$ represents exposure duration $\left(\mathrm{d} \cdot \mathrm{a}^{-1}\right), E F$ represents exposure frequency $(\mathrm{a}), B W$ represents body weight $(\mathrm{kg})$ and $A L$ represents average lifetime (a). When $H I$ was less than one, it might be inferred that such an exposure was unlikely at risk of toxicity or a given health problem, and vice versa.

\subsubsection{Carcinogenic health risk assessment}

For carcinogenic substances, it had apparently no threshold effect. Trace amounts of carcinogens would adversely affect human health. Cancer risk involved a simple calculation of risk values (Risk).

Exposure at low levels:

$$
\text { Risk }=C D I \times S F
$$

If Risk at low-dose value bigger than 0.01 , it should be calculated at high dose exposure: 


$$
\begin{aligned}
R \text { isk } & =1-\exp (-C D I \times S F) \\
S F & =\frac{U R F \times B W \times C F}{I R \times A R}
\end{aligned}
$$

Where $S F$ represents slope factor $\left(\mathrm{kg} \cdot \mathrm{d} \cdot \mathrm{mg}^{-1}\right)$, are used to estimate the risk of cancer associated with exposure to a carcinogenic or potentially carcinogenic substance. URF represents unit risk factor $\left(\mathrm{m}^{3} / \mu \mathrm{g}\right), C F$ represents conversion factor $(1000 \mu \mathrm{g} / \mathrm{mg}), A R$ represents absorption rate. (USEPA), OSHA (the occupational safety and health agency) suggested that people can tolerate the risk of cancer at $1 \times 10^{-6}[11]$.

The study used the risk assessment methods, the data of dose-response relationship with the United States EPA's integrated risk information system (IRIS) data evaluation. Health risk in this area of VOCs was evaluated through the risk index calculation of pollutants. The corresponding calculation formula of pollutants in RfD and $S F$ were shown in table 5. That was described as the followings: the frequency of exposure for 30 years, the exposure time for the working time (eight hours a day). According to the EPA's data, adult daily inhaled air volume was $20 \mathrm{~m}^{3} \cdot \mathrm{d}^{-1}$, the average life expectancy was 70 years, the average weight of adult was $60 \mathrm{~kg}$ (It accorded with the average height of Chinese), the pollutant absorption rate was $90 \%$.

The reference dose and slope factor of VOCs listed in Table 5 were substituted into formula (1)-(4). The Chronic daily intake and Health risk were shown in Table 6.

\begin{tabular}{|c|c|c|c|}
\hline chemical composition & $\begin{array}{c}\text { RfD } \\
{\left[\mathrm{mg} \cdot(\mathrm{kg} \cdot \mathrm{d})^{-1}\right]}\end{array}$ & $\begin{array}{c}\text { URF } \\
\left(m^{3} \bullet \mu g\right)\end{array}$ & $\begin{array}{c}S F \\
\left(\mathrm{~kg} \cdot \mathrm{d} \cdot \mathrm{mg}^{-1}\right)\end{array}$ \\
\hline formaldehyde & $2 \times 10^{-1}$ & $1.3 \times 10^{-5}$ & $4.3 \times 10^{-2}$ \\
\hline benzene & $4 \times 10^{-3}$ & $7.8 \times 10^{-6}$ & $2.6 \times 10^{-2}$ \\
\hline toluene & $8 \times 10^{-2}$ & & \\
\hline ethyl benzene & $1 \times 10^{-1}$ & & \\
\hline xylene & $2 \times 10^{-1}$ & & \\
\hline styrene & $2 \times 10^{-1}$ & & \\
\hline naphthalene & $2 \times 10^{-2}$ & & \\
\hline
\end{tabular}

Table 5. Toxicity factor for chemicals contained in the surgical smoke of concern

\section{Results}

With USEPA's health risk assessment model, the health risks of volatile organic compounds (VOCs) in surgical smoke were evaluated. From table 6, the risk index HI (non-carcinogenic risk) of each mode was between $6.60 \times 10^{-2}$ and $3.07 \times 10^{-1}$, among which benzene compounds were the main risk factor. The carcinogenic risk index was ranging from $3.77 \times 10^{-5}$ to $1.05 \times 10^{-4}$. The effect of VOCs on human health in surgical smoke was mainly carcinogenic risk. Formaldehyde and benzene compounds were the most hazardous substances in surgical smoke [21]. There is no definite standard for health risk assessment in China. Referring to the European and American standards, carcinogenic risk standards are ranging from $10^{-5}$ to $10^{-6}$, and the non-carcinogenic risk, when the risk index do not exceed 1, will not cause significant harm to human health [11]. From Table 6, the non-carcinogenic risk value was within the safe range, indicating that these pollutants did not cause significant non-carcinogenic harm to the exposed human health. But its carcinogenic index higher than the United States EPA's cancer risk value $\left(1 \times 10^{-6}\right)$ [11], showed that formaldehyde and benzene in surgical smoke had harmful effect on human health. Long-term exposure of such surgical smoke would be harmful to human health and have a great risk of cancer [22].

The height of $1.671 \mathrm{~m}$, the weight of $60 \mathrm{~kg}$ and other set parameters used in this study were the average values of Chinese. If the average values in the United States were used to calculate, the results were shown in Appendix A. The risk index HI (non-carcinogenic risk) of each mode was ranging from $1.34 \times 10^{-2}$ to $1.07 \times 10^{-1}$ and the carcinogenic risk index was ranging from $1.40 \times 10^{-5}$ to $3.90 \times 10^{-5}$. As a result, the non-carcinogenic risk value was also within the safe range, but its carcinogenic index was higher than the United States EPA's cancer risk value $\left(1 \times 10^{-6}\right)$. Overall it 
seemed to say that either the risk index HI (non-carcinogenic risk) or the carcinogenic index, the United States had a slightly lower value than China. This was because Americans were taller on average and the leak height was greater, thereby reducing the concentration of inhaled pollutants. At the same time, Americans were heavier on average that the values of CDI were reduced, thus making the risk value lower. Thus, even at the same leak concentration, various persons were different in height and weight, resulting in different risk values. In addition, the varieties of surgical smoke were numerous [15]. Because the detection technology in the references was limited, and the study only selected several representative substances of VOCs, the real values must be greater. If all VOCs were considered in the calculation, the risk index $\mathrm{HI}$ (non-carcinogenic risk) was very possible to exceed the safe range. For example, acrylamide, polycyclic aromatic hydrocarbons and benzopyrene were taken into account.

Table 6. Chronic daily intake (CDI) and Health risk of VOCs

\begin{tabular}{|c|c|c|c|c|}
\hline Pattern & chemical composition & $\begin{array}{c}\mathrm{CDI} \\
{\left[\mathrm{mg} \bullet(\mathrm{kg} \cdot \mathrm{d})^{-1}\right]}\end{array}$ & HI & Risk \\
\hline \multirow[t]{8}{*}{1} & formaldehyde & $9.96 \times 10^{-4}$ & $4.98 \times 10^{-3}$ & $4.28 \times 10^{-5}$ \\
\hline & benzene & $1.12 \times 10^{-3}$ & $2.80 \times 10^{-1}$ & $2.91 \times 10^{-5}$ \\
\hline & toluene & $1.01 \times 10^{-3}$ & $1.26 \times 10^{-2}$ & \\
\hline & ethyl benzene & $2.25 \times 10^{-4}$ & $2.25 \times 10^{-3}$ & \\
\hline & xylene & $4.25 \times 10^{-5}$ & $2.13 \times 10^{-4}$ & \\
\hline & styrene & $1.43 \times 10^{-4}$ & $7.15 \times 10^{-4}$ & \\
\hline & naphthalene & $1.15 \times 10^{-4}$ & $5.75 \times 10^{-3}$ & \\
\hline & risk index & & $3.07 \times 10^{-1}$ & $7.19 \times 10^{-5}$ \\
\hline \multirow[t]{8}{*}{2} & formaldehyde & $7.09 \times 10^{-4}$ & $3.55 \times 10^{-3}$ & $3.05 \times 10^{-5}$ \\
\hline & benzene & $2.76 \times 10^{-4}$ & $6.90 \times 10^{-2}$ & $7.18 \times 10^{-6}$ \\
\hline & toluene & $2.77 \times 10^{-4}$ & $3.46 \times 10^{-3}$ & \\
\hline & ethyl benzene & $5.74 \times 10^{-5}$ & $5.74 \times 10^{-4}$ & \\
\hline & xylene & $6.36 \times 10^{-6}$ & $3.18 \times 10^{-5}$ & \\
\hline & styrene & $2.7 \times 10^{-5}$ & $1.35 \times 10^{-4}$ & \\
\hline & naphthalene & $<7.09 \times 10^{-7}$ & $<3.55 \times 10^{-5}$ & \\
\hline & risk index & & $6.60 \times 10^{-2}$ & $3.77 \times 10^{-5}$ \\
\hline \multirow[t]{8}{*}{3} & formaldehyde & $1.35 \times 10^{-3}$ & $6.75 \times 10^{-3}$ & $6.21 \times 10^{-5}$ \\
\hline & benzene & $9.18 \times 10^{-5}$ & $2.30 \times 10^{-2}$ & $2.48 \times 10^{-6}$ \\
\hline & toluene & $3.9 \times 10^{-5}$ & $4.88 \times 10^{-4}$ & \\
\hline & ethyl benzene & $4.04 \times 10^{-5}$ & $4.04 \times 10^{-4}$ & \\
\hline & xylene & $1.28 \times 10^{-5}$ & $6.40 \times 10^{-5}$ & \\
\hline & styrene & $3.05 \times 10^{-5}$ & $1.53 \times 10^{-4}$ & \\
\hline & naphthalene & $2.2 \times 10^{-4}$ & $1.10 \times 10^{-2}$ & \\
\hline & risk index & & $6.67 \times 10^{-2}$ & $6.46 \times 10^{-5}$ \\
\hline \multirow[t]{8}{*}{4} & formaldehyde & $2.13 \times 10^{-3}$ & $1.07 \times 10^{-2}$ & $9.16 \times 10^{-5}$ \\
\hline & benzene & $5.27 \times 10^{-4}$ & $1.32 \times 10^{-1}$ & $1.37 \times 10^{-5}$ \\
\hline & toluene & $2.24 \times 10^{-4}$ & $2.80 \times 10^{-3}$ & \\
\hline & ethyl benzene & $4.47 \times 10^{-5}$ & $4.47 \times 10^{-4}$ & \\
\hline & xylene & $9.18 \times 10^{-6}$ & $4.59 \times 10^{-5}$ & \\
\hline & styrene & $3.4 \times 10^{-5}$ & $1.70 \times 10^{-4}$ & \\
\hline & naphthalene & $<7.09 \times 10^{-7}$ & $<3.55 \times 10^{-5}$ & \\
\hline & risk index & & $1.46 \times 10^{-1}$ & $1.05 \times 10^{-4}$ \\
\hline
\end{tabular}

\section{Discussion}

Studies during the past four decades has demonstrated that surgical smoke generated from the use of energy-generating devices in surgery contained toxic and biohazardous substances that 
present health risks to perioperative team members and patients [23]. The other argument was that surgeon long-term exposure to the surgical smoke could directly affect the surgical quality. The problems experienced by the nurses and surgeons as a result of exposure to surgical smoke included: headache, watering of the eyes, cough, sore throat, bad odours absorbed in the hair, nausea, drowsiness, dizziness, sneezing and rhinitis [24]. Paying attention to the effect of surgical smoke could surely promote the precautions that can be taken against surgical smoke.

The goal of human health risk management is to control the carcinogenic risk of carcinogens in a safe range. If the risk of cancer is beyond the range of safety, some measures should be taken to control the discharge of pollutants to ensure the health of the operating theater staff. Specific measures to be taken as the followings: we could increase the air velocity of fresh air system to reduce the concentration of harmful substances, but it could not fundamentally solve the problem; it was recommended to use special cleaning device for removing formaldehyde and benzene, greatly reducing the concentration of harmful substances. The three components of an efficient evacuation system should be: a capturing device that did not interfere with surgical procedure; a vacuum source which could properly remove the smoke by strong enough suction; and a filtration system that was able to filter the smoke and make a safer environment [25]. If efficient control measures were taken, the emission concentration of formaldehyde and benzene would be lower than the values shown in Table 7 . These measures would remove almost all biological material that might be present and most of the harmful chemicals, and eliminate the smell of most smoke [6].

This study evaluated the health risk of VOCs in the operation room based on the assessment model of atmospheric environmental health risk. It was a valuable and meaningful study. However, due to the differences of economic development, operating room environment, medical level and human species in different countries, there would be some differences in human exposure and dose-response relationship. The selection of model and parameters were mainly from the USEPA. Because some factors were ignored, the selected criteria may had some impact on the calculation results. Therefore, there were some uncertainties and limitations in the calculation of risk value and health risk assessment, which need further research and improvement.

Table7. The suggested control concentration by treatment devices

\begin{tabular}{ccccc}
\hline $\begin{array}{c}\text { chemical } \\
\text { composition } \\
\left(\mathbf{m g} / \mathbf{m}^{3}\right)\end{array}$ & $\mathbf{1}$ & $\mathbf{2}$ & 3 & $\mathbf{4}$ \\
\hline $\begin{array}{c}\text { formaldehyde } \\
\text { benzene }\end{array}$ & $<1.94 \times 10^{-3}$ & $<2.65 \times 10^{-3}$ & $<3.14 \times 10^{-3}$ & $<2.86 \times 10^{-3}$ \\
\hline
\end{tabular}

\section{Conclusions}

For Chinese surgeon, the risk index HI (non-carcinogenic risk) of each mode was ranging from $6.60 \times 10^{-2}$ to $3.07 \times 10^{-1}$ and the carcinogenic risk index was ranging from $3.77 \times 10^{-5}$ to $1.05 \times 10^{-4}$. For American surgeon, the risk index $\mathrm{HI}$ (non-carcinogenic risk) of each mode was ranging from $1.34 \times 10^{-2}$ to $1.07 \times 10^{-1}$ and the carcinogenic risk index was ranging from $1.40 \times 10^{-5}$ to $3.90 \times 10^{-5}$. Whether it's Chinese surgeon or American surgeon, the non-carcinogenic risk value was within the safe range, but its carcinogenic index was higher than the United States EPA's cancer risk value $\left(1 \times 10^{-6}\right)$. Formaldehyde and benzene compounds were the most hazardous substances in surgical smoke. The impact of surgical smoke on human health was mainly carcinogenic risk. Therefore, corresponding control measures need to be taken. If efficient control measures were taken, the emission concentration of formaldehyde and benzene would be lower than the values shown in Table 7 . This study demonstrated that the potential harm of surgical smoke exist. Further research is needed to verify the applicability of the health risk assessment and should focus on comparing the smoke produced by different energy-based devices and the long-term consequences of smoke exposure.

Supplementary Materials: The following is available online at https://www.epa.gov/iris, Table 5: Toxicity factor for chemicals contained in the surgical smoke of concern. 
Acknowledgments: This study was financially supported by National Natural Science Foundation of China (Grant No.51508228), Pearl River S\&T Nova Program of Guangzhou (201710010091) and the Fundamental Research Funds for the Central Universities.

Author Contributions: Shaohua She and Gang Lu conceived the whole frame of the article; Wah Yang performed answers to medical knowledge; Shaohua She and Mianwei Hong analyzed the data; Shaohua She contributed model calculation; Mianwei Hong and Lingfei Zhu verified the mode data; Shaohua She wrote the paper.

Conflicts of Interest: The authors declare no conflict of interest.

\section{Appendix A}

The height $(1.771 \mathrm{~m})$, weight $(70 \mathrm{~kg})$ and other parameters used in this part were the average values of American.

Table A1. The concentration of surgical smoke that surgeon inhaled i.e., the concentration at one point $(0.240,0,1.544) \quad$ Unit: $\mathrm{kg} / \mathrm{m}^{3}$

\begin{tabular}{ccccc}
\hline $\begin{array}{c}\text { chemical composition } \\
\left(\mathbf{k g} / \mathbf{m}^{3}\right)\end{array}$ & $\mathbf{1}$ & $\mathbf{2}$ & 3 & $\mathbf{4}$ \\
\hline formaldehyde & $7.76 \times 10^{-12}$ & $5.53 \times 10^{-12}$ & $1.05 \times 10^{-11}$ & $1.66 \times 10^{-11}$ \\
benzene & $8.76 \times 10^{-12}$ & $2.16 \times 10^{-12}$ & $7.16 \times 10^{-13}$ & $4.09 \times 10^{-12}$ \\
toluene & $7.83 \times 10^{-12}$ & $2.16 \times 10^{-12}$ & $3.04 \times 10^{-13}$ & $1.74 \times 10^{-12}$ \\
ethyl benzene & $1.76 \times 10^{-12}$ & $4.48 \times 10^{-13}$ & $3.15 \times 10^{-13}$ & $3.48 \times 10^{-13}$ \\
o-xylene & $3.32 \times 10^{-13}$ & $4.98 \times 10^{-14}$ & $9.95 \times 10^{-14}$ & $7.16 \times 10^{-14}$ \\
styrene & $1.11 \times 10^{-12}$ & $2.10 \times 10^{-13}$ & $2.38 \times 10^{-13}$ & $2.65 \times 10^{-13}$ \\
naphthalene & $8.96 \times 10^{-13}$ & $<5.53 \times 10^{-15}$ & $1.17 \times 10^{-12}$ & $<5.53 \times 10^{-15}$ \\
\hline
\end{tabular}

Table A2. The concentration of surgical smoke that surgeon inhaled i.e., the concentration at one point $(0.240,0,1.544)$ Unit: $\mathrm{mg} / \mathrm{m}^{3}$

\begin{tabular}{ccccc}
\hline $\begin{array}{c}\text { chemical composition } \\
\left(\mathbf{m g} / \mathbf{m}^{3}\right)\end{array}$ & $\mathbf{1}$ & $\mathbf{2}$ & $\mathbf{3}$ & $\mathbf{4}$ \\
\hline formaldehyde & $7.76 \times 10^{-6}$ & $5.53 \times 10^{-6}$ & $1.05 \times 10^{-5}$ & $1.66 \times 10^{-5}$ \\
benzene & $8.76 \times 10^{-6}$ & $2.16 \times 10^{-6}$ & $7.16 \times 10^{-7}$ & $4.09 \times 10^{-6}$ \\
toluene & $7.83 \times 10^{-6}$ & $2.16 \times 10^{-6}$ & $3.04 \times 10^{-7}$ & $1.74 \times 10^{-6}$ \\
ethyl benzene & $1.76 \times 10^{-6}$ & $4.48 \times 10^{-6}$ & $3.15 \times 10^{-7}$ & $3.48 \times 10^{-7}$ \\
o-xylene & $3.32 \times 10^{-7}$ & $4.98 \times 10^{-8}$ & $9.95 \times 10^{-8}$ & $7.16 \times 10^{-8}$ \\
styrene & $1.11 \times 10^{-6}$ & $2.10 \times 10^{-7}$ & $2.38 \times 10^{-7}$ & $2.65 \times 10^{-7}$ \\
naphthalene & $8.96 \times 10^{-7}$ & $<5.53 \times 10^{-9}$ & $1.17 \times 10^{-6}$ & $<5.53 \times 10^{-9}$ \\
\hline
\end{tabular}

Table A3. Toxicity factor for chemicals contained in the surgical smoke of concern

\begin{tabular}{cccc}
\hline chemical composition & $\begin{array}{c}\mathbf{R f D} \\
\left.[\mathbf{m g} \cdot(\mathbf{k g} \cdot \mathbf{d}))^{-1}\right]\end{array}$ & $\begin{array}{c}\text { URF } \\
\left(\mathbf{m}^{3} \bullet \boldsymbol{\mu g}\right)\end{array}$ & $\begin{array}{c}\mathrm{SF} \\
\mathbf{( k g} \cdot \mathbf{d} \cdot \mathbf{m g} \mathbf{g}^{-1} \mathbf{)}\end{array}$ \\
\hline formaldehyde & $2 \times 10^{-1}$ & $1.3 \times 10^{-5}$ & $4.6 \times 10^{-2}$ \\
benzene & $4 \times 10^{-3}$ & $7.8 \times 10^{-6}$ & $2.7 \times 10-2$ \\
toluene & $8 \times 10^{-2}$ & & \\
ethyl benzene & $1 \times 10^{-1}$ & & \\
xylene & $2 \times 10^{-1}$ & & \\
styrene & $2 \times 10^{-1}$ & & \\
naphthalene & $2 \times 10^{-2}$ & & \\
\hline
\end{tabular}


Table A4. Chronic daily intake (CDI) and Health risk of VOCs

\begin{tabular}{|c|c|c|c|c|}
\hline Pattern & chemical composition & $\begin{array}{c}\mathrm{CDI} \\
{\left[\mathrm{mg} \bullet(\mathrm{kg} \bullet \mathrm{d})^{-1}\right]} \\
\end{array}$ & HI & Risk \\
\hline \multirow[t]{8}{*}{1} & formaldehyde & $3.47 \times 10^{-4}$ & $1.74 \times 10^{-3}$ & $1.60 \times 10^{-5}$ \\
\hline & benzene & $3.92 \times 10^{-4}$ & $9.80 \times 10^{-2}$ & $1.06 \times 10^{-5}$ \\
\hline & toluene & $3.50 \times 10^{-4}$ & $4.38 \times 10^{-3}$ & \\
\hline & ethyl benzene & $7.87 \times 10^{-5}$ & $7.87 \times 10^{-4}$ & \\
\hline & xylene & $1.48 \times 10^{-5}$ & $7.40 \times 10^{-5}$ & \\
\hline & styrene & $4.96 \times 10^{-5}$ & $2.48 \times 10^{-4}$ & \\
\hline & naphthalene & $4.00 \times 10^{-5}$ & $2.00 \times 10^{-3}$ & \\
\hline & risk index & & $1.07 \times 10^{-1}$ & $2.66 \times 10^{-5}$ \\
\hline \multirow[t]{8}{*}{2} & formaldehyde & $2.47 \times 10^{-4}$ & $1.24 \times 10^{-3}$ & $1.14 \times 10^{-5}$ \\
\hline & benzene & $9.65 \times 10^{-5}$ & $2.41 \times 10^{-2}$ & $2.61 \times 10^{-6}$ \\
\hline & toluene & $9.65 \times 10^{-5}$ & $1.21 \times 10^{-3}$ & \\
\hline & ethyl benzene & $2.00 \times 10^{-4}$ & $2.00 \times 10^{-3}$ & \\
\hline & xylene & $2.23 \times 10^{-6}$ & $1.12 \times 10^{-5}$ & \\
\hline & styrene & $9.39 \times 10^{-6}$ & $4.70 \times 10^{-5}$ & \\
\hline & naphthalene & $<2.47 \times 10^{-7}$ & $<1.24 \times 10^{-5}$ & \\
\hline & risk index & & $2.86 \times 10^{-2}$ & $1.40 \times 10^{-5}$ \\
\hline \multirow[t]{8}{*}{3} & formaldehyde & $4.69 \times 10^{-4}$ & $2.35 \times 10^{-3}$ & $2.16 \times 10^{-5}$ \\
\hline & benzene & $3.20 \times 10^{-5}$ & $8.00 \times 10^{-3}$ & $8.64 \times 10^{-7}$ \\
\hline & toluene & $1.36 \times 10^{-5}$ & $1.70 \times 10^{-4}$ & \\
\hline & ethyl benzene & $1.41 \times 10^{-5}$ & $1.41 \times 10^{-4}$ & \\
\hline & xylene & $4.45 \times 10^{-6}$ & $2.23 \times 10^{-5}$ & \\
\hline & styrene & $1.06 \times 10^{-5}$ & $5.30 \times 10^{-5}$ & \\
\hline & naphthalene & $5.23 \times 10^{-5}$ & $2.62 \times 10^{-3}$ & \\
\hline & risk index & & $1.34 \times 10^{-2}$ & $2.25 \times 10^{-5}$ \\
\hline \multirow[t]{8}{*}{4} & formaldehyde & $7.42 \times 10^{-4}$ & $3.71 \times 10^{-3}$ & $3.41 \times 10^{-5}$ \\
\hline & benzene & $1.83 \times 10^{-4}$ & $4.58 \times 10^{-2}$ & $4.94 \times 10^{-6}$ \\
\hline & toluene & $7.78 \times 10^{-5}$ & $9.73 \times 10^{-4}$ & \\
\hline & ethyl benzene & $1.56 \times 10^{-5}$ & $1.56 \times 10^{-4}$ & \\
\hline & xylene & $3.20 \times 10^{-6}$ & $1.60 \times 10^{-5}$ & \\
\hline & styrene & $1.18 \times 10^{-5}$ & $5.90 \times 10^{-5}$ & \\
\hline & naphthalene & $<2.47 \times 10^{-7}$ & $<1.24 \times 10^{-5}$ & \\
\hline & risk index & & $5.07 \times 10^{-2}$ & $3.90 \times 10^{-5}$ \\
\hline
\end{tabular}

\section{References}

1. Brace, M. D.; Stevens, E.; Taylor, S. M.; et al. 'the air that we breathe': assessment of laser and electrosurgical dissection devices on operating theater air quality. J. Otolaryngol-head. N. 2014, 43, 39.

2. Fitzgerald, J. E.; Malik, M.; Ahmed, I. A single-blind controlled study of electrocautery and ultrasonic scalpel smoke plumes in laparoscopic surgery. Surg. Endosc. 2012, 26, 337-42.

3. Okoshi, K.; Kobayashi, K.; Kinoshita, K.; Tomizawa, Y.; Hasegawa, S.; Sakai, Y. Health risks associated with exposure to surgical smoke for surgeons and operation room personnel. Surg. Today 2015, 45, 957.

4. Ragde, S. F.; Jørgensen, R. B.; Føreland, S. Characterisation of exposure to ultrafine particles from surgical smoke by use of a fast mobility particle sizer. Ann. Occup. Hyg. 2016, 60, 860.

5. Hill, D. S.; O'Neill, J. K.; Powell, R. J.; Oliver, D. W. Surgical smoke - a health hazard in the operating theatre: a study to quantify exposure and a survey of the use of smoke extractor systems in UK plastic surgery units. J. Plast. Reconstr. Aes. 2012, 65, 911-916.

6. Schultz, L. An analysis of surgical smoke plume components, capture, and evacuation. Aorn J. 2014, 99, 289-298. 
7. Cipolla, M.; Izzotti, A.; Ansaldi, F.; Durando, P.; Piccardo, M. T. Volatile organic compounds in anatomical pathology wards: comparative and qualitative assessment of indoor airborne pollution. Inter. J. Env. Res. Pub. Heal. 2017, 14.

8. Tseng, H. S.; Liu, S. P.; Uang, S. N.; et al. Cancer risk of incremental exposure to polycyclic aromatic hydrocarbons in electrocautery smoke for mastectomy personnel. World J. Surg. Oncol. 2014, 12, 31.

9. Tran, K., Cimon, K., Severn, M., Pessoasilva, C. L., \& Conly, J. Aerosol generating procedures and risk of transmission of acute respiratory infections to healthcare workers: a systematic review. Plos One 2012, 7 , e35797.

10. Mowbray, N.; Ansell, J.; Warren, N.; Wall, P.; Torkington, J. Is surgical smoke harmful to theater staff? a systematic review. Surg. Endosc. 2013, 27, 3100-7.

11. USEPA. Integrated risk information system (IRIS). 2003. Available online: https://www.epa.gov/iris (accessed on 12 July 2017).

12. Huang, L.; Mo, J.; Sundell, J.; Fan, Z.; Zhang, Y. Health risk assessment of inhalation exposure to formaldehyde and benzene in newly remodeled buildings, Beijing. Plos One 2013, 8, e79553.

13. Zhigui, H.; Guiying, L.; Jiangyao, C.; Yong, H.; Taicheng, A.; Chaosheng, Z. Pollution characteristics and health risk assessment of volatile organic compounds emitted from different plastic solid waste recycling workshops. Environ. Int. 2015, 77, 85.

14. Du, Z.; Mo, J.; Zhang, Y.; Xu, Q. Benzene, toluene and xylenes in newly renovated homes and associated health risk in guangzhou, china. Build. Environ. 2014, 72, 75-81.

15. Krones, C. J.; Conze, J.; Hoelzl, F.; et al. Chemical composition of surgical smoke produced by electrocautery, harmonic scalpel and argon beaming - a short study. Eur. Surg. 2007, 39, 118-121.

16. Wu, Y. C.; Tang, C. S.; Huang, H. Y.; et al. Chemical production in electrocautery smoke by a novel predictive model. Eur. Surg. Res. 2011, 46, 102-107.

17. Tramontini, C. C.; Galvão, C. M.; Claudio, C. V.; Ribeiro, R. P.; Martins, J. T. Composition of the electrocautery smoke: integrative literature review. Rev. Esc. Enferm USP 2016, 50, 144.

18. Zhu, L. M.; Rui, X. P.; Yao, L. I.; Xue-Xiang, Y. U. Gaussian diffusion model on leakage and diffusion simulation of coalbed methane. Comput. Eng. Des. 2014, 35, 1754-1759.

19. Buchholz, S.; Krein, A., Junk, J.; Heinemann, G.; Hoffmann, L. Simulation of urban-scale air pollution patterns in luxembourg: contributing sources and emission scenarios. Environ. Model. Assess. 2013, 18, 271-283.

20. Durmusoglu, E.; TaspiNar, F.; KarademkiR, A. Health risk assessment of btex emissions in the landfill environment. J. Hazard. Mater. 2010, 176, 870.

21. Dong, H. C.; Choi, S. H.; Dong, H. K. Influence of surgical smoke on indoor air quality in hospital operating rooms. Aerosol Air Qual. Res. 2017, 17, 821-830.

22. Chavis, S.; Wagner, V.; Becker, M., Bowerman, M. I.; Jamias, M. S. Clearing the air about surgical smoke: an education program. Aorn J. 2016, 103, 289.

23. Ilce, A.; Yuzden, G. E.; Giersbergen, M. Y. V. The examination of problems experienced by nurses and doctors associated with exposure to surgical smoke and the necessary precautions. J. Clin. Nurs. 2016, 26, 1555-1561.

24. Jamal, S.; Hassan, M.; Farooqi, M.; Ali, S. Surgical smoke-concern for both doctors and patients. Indian J. Surg. 2015, 77, 1494.

25. Shah, N. R. Commentary on: "surgical smoke - a health hazard in the operating theatre: a study to quantify exposure and a survey of the use of smoke extractor systems in UK plastic surgery units". Ann. Med. Surg. 2012, 1, 23. 